\title{
Long-Term Properties of Different Fiber Reinforcement Effect on Fly Ash-Based Geopolymer Composite
}

\author{
Rihards Gailitis ${ }^{1, *}$, Andina Sprince ${ }^{1}$, Tomass Kozlovskis ${ }^{1}$, Liga Radina ${ }^{1}$, Leonids Pakrastins ${ }^{1}$ \\ and Nikolai Vatin ${ }^{2}$ (I) \\ 1 Faculty of Civil Engineering, Riga Technical University, LV-1658 Riga, Latvia; andina.sprince@rtu.lv (A.S.); \\ tomass.kozlovskis@rtu.lv (T.K.); liga.radina@rtu.lv (L.R.); leonids.pakrastins@rtu.lv (L.P.) \\ 2 Peter the Great St. Petersburg Polytechnic University, 195251 St. Petersburg, Russia; vatin@mail.ru \\ * Correspondence: rihards.gailitis@edu.rtu.lv
}

check for

updates

Citation: Gailitis, R.; Sprince, A.; Kozlovskis, T.; Radina, L.;

Pakrastins, L.; Vatin, N. Long-Term

Properties of Different Fiber

Reinforcement Effect on Fly

Ash-Based Geopolymer Composite.

Crystals 2021, 11, 760. https://

doi.org/10.3390/cryst11070760

Academic Editors: Michele Iafisco and Helmut Cölfen

Received: 6 May 2021

Accepted: 24 June 2021

Published: 29 June 2021

Publisher's Note: MDPI stays neutral with regard to jurisdictional claims in published maps and institutional affiliations.

Copyright: (C) 2021 by the authors. Licensee MDPI, Basel, Switzerland. This article is an open access article distributed under the terms and conditions of the Creative Commons Attribution (CC BY) license (https:// creativecommons.org/licenses/by/ $4.0 /)$.
Abstract: Geopolymer composites have been around only for 40 years. Nowadays, they are used in buildings and infrastructures of various kinds. A geopolymer's main benefit is that it is a green material that is partially made by utilizing waste products. The carbon footprint from geopolymer matrix manufacturing is at least two times less than Portland cement manufacturing. Due to the nature of the geopolymer manufacturing process, there is a high risk of shrinkage that could develop unwanted micro-cracks that could reduce strength and create higher creep strains. Because of this concern, a common strategy to reduce long-term strains of the material, such as shrinkage and creep, is to add fiber reinforcement that would constrain crack development in the material. This article aims to determine how various kinds and amounts of different fiber reinforcement affect fly ash-based geopolymer composites' creep strains in compression. Specimen mixes were produced with $1 \%$ steel fibers, $1 \%$ polypropylene fibers, $5 \%$ polypropylene fibers, and without fibers (plain geopolymer). For creep and shrinkage testing, cylindrical specimens $\varnothing 46 \times 190 \mathrm{~mm}$ were used. The highest creep resistance was observed in $5 \%$ polypropylene fiber specimens, followed by $1 \%$ polypropylene fiber, plain, and $1 \%$ steel fiber specimens. The highest compressive strength was observed in $1 \%$ polypropylene fiber specimens, followed by plain specimens, $1 \%$ steel fiber specimens, and $5 \%$ polypropylene fiber-reinforced specimens. The only fiber-reinforced geopolymer mix with improved long-term properties was observed with $1 \%$ polypropylene fiber inclusion, whereas other fiberintroduced mixes showed significant decreases in long-term properties. The geopolymer composite mix with $1 \%$ polypropylene fiber reinforcement showed a reduction in creep strains of $31 \%$ compared to the plain geopolymer composite.

Keywords: fly ash-based geopolymer composite; long-term properties; fiber-reinforced geopolymer

\section{Introduction}

In recent years, there has been increased interest in geopolymer composites. A geopolymer composite (GP/GPC) is a three-dimensional inorganic material with multiple beneficial qualities, such as a significantly reduced carbon footprint caused by its manufacturing, increased resistance to high-temperature exposure, and resistance to various kinds of acid exposure [1-4]. It is reckoned that the manufacturing of 1 ton of kaolin-based geopolymer cement production generates 0.180 tons of $\mathrm{CO}_{2}$, unlike ordinary Portland cement (OPC) concrete, which has a carbon footprint that is up to 6 times greater. At the same time, the cost margin varies from $7 \%$ lower to $39 \%$ higher than OPC $[5,6]$.

The creep behavior of cementitious binders significantly affects the durability and serviceability of concrete structures. There have been several studies focused on the creep in compression. Most of them have found that, in most cases, the creep of a geopolymer composite is less than OPC [7-10].

Drying shrinkage is also a factor that influences long-term strains. According to capillary tension theory, it has been claimed that shrinkage strains are caused by capillary 
pressure in the pore walls. For a geopolymer composite, the ways to reduce the pore amount include the modification of pore structure or reduction of water loss during curing, or the inclusion of inert or reactive fillers and fibers [11-13]. In certain cases, the addition of fibers can significantly reduce or even eliminate shrinkage strains. It has been claimed that $0.5 \mathrm{vol} \%$ of polypropylene fibers or steel fibers reduce the shrinkage significantly, but the inclusion of $2 \mathrm{vol} \%$ of steel fibers results in almost no shrinkage [14-16].

To enhance mechanical properties and, therefore OPC structural applications, fiber reinforcement is used. Two groups of fibers are used: (i) fibers with a low modulus of elasticity and high elongation properties (such as polypropylene, nylon, polyethene, etc., fibers) and (ii) fibers with a high modulus of elasticity (such as carbon, steel, and glass fibers). In general, the first group does not improve the strength. Instead, they improve fracture toughness and resistance to impact and explosion loads. The second group does effectively enhance the strength and stiffness properties [17].

Polypropylene fibers (PPFs) are the most often used commercial fibers due to their cost compared to steel fibers as well as their corrosion resistance [18]. They also have many advantages over other synthetic fibers, mostly due to their lightweight properties, cost efficiency, low thermal conductivity, and resistance to acid and alkali attacks [17]. Furthermore, the plain polypropylene fibers have the ecological benefit of decomposing in the natural environment, unlike polypropylene fiber fabric [19]. According to previous studies, PPF incorporation improves splitting tensile strength and flexural strength, creep behavior, tensile strength, and shrinkage reduction. It has been claimed that the incorporation of $1 \%$ PPF results in the optimum performance enhancement to splitting and flexural strength performance increases. Still, the fiber incorporation above $3 \%$ leads to a decrease in workability [17].

Steel fibers (SFs) are increasingly used as auxiliary reinforcement for temporary load cases, partial substitution of conventional reinforcement, and a total replacement of traditional reinforcement in overall compression. Due to SF-reinforced concrete structure having good overall durability and mechanical performance, it has gained popularity, and the conventional reinforcement has been partially or completely replaced in statically indeterminate structures [20]. Steel fiber increases mechanical properties such as the strength and stiffness of concrete [17]. They are used in structural applications where it is important to control the cracking processes, such as industrial pavements and tunnel linings and ultra-high performance steel fiber-reinforced structures, such as cooling towers, silos, sewage, and industrial wastewater tunnels and treatment plants. The addition of $\mathrm{SF}$ increases deformation and ductility capacity in cases where the maximum flexural load is exceeded $[20,21]$. It has been revealed that the distribution and orientation of SF significantly affect the strengthening effect of concrete. Also, the aggregate should not exceed three-quarters of the length of fiber or $25 \mathrm{~mm}$ [22].

Due to the previously stated environmental concerns and the apparent benefits of geopolymer composite and fiber incorporation in OPC, it is necessary to evaluate the fiber influence on creep and shrinkage strain development in geopolymer composites.

\section{Materials and Methods}

A geopolymer cylindrical specimen matrix was based on fly ash sourced from the local power plant in Skawina city (Poland). This kind of fly ash is suitable for geopolymers because of its physical properties and chemical composition. The fly ash contains spherical aluminosilicate particles and is rich with oxides such as $\mathrm{SiO}_{2}(47.81 \%)$ and $\mathrm{Al}_{2} \mathrm{O}_{3}(22.80 \%)$. The high value of $\mathrm{SiO}_{2}$ and $\mathrm{Al}_{2} \mathrm{O}_{3}$ provides advantages for geopolymerization.

Geopolymer specimens were prepared using sodium promoter, fly ash, and sand (the ratio of sand to fly ash was 1:1). The activation solution was made using a 10-molar (10 M) $\mathrm{NaOH}$ solution combined with the sodium silicate R-145 solution (with a molar module of 2.5 and a density of around $1.45 \mathrm{~g} / \mathrm{cm}^{3}$, with a ratio of $\mathrm{NaOH}$ and $\mathrm{Na}_{2} \mathrm{O}+\mathrm{SiO}_{2}$ of 1:2.5). The technical $\mathrm{NaOH}$ in flake form and tap water was used instead of distilled water to make $\mathrm{NaOH}$ solution. The alkaline solution was prepared by pouring sodium silicate 
and water over solid sodium hydroxide into the aqueous solution of sodium silicate and water. The solution was mixed and left over night until its temperature stabilized and the concentrations were equalized. The fly ash, sand, and alkaline solution were mixed for about 15 min using a low-speed mixing machine in order to create a homogenous paste. A quarter of the specimens were reinforced with $1 \%$ (by mass) of short PPFs (approximately $3 \mathrm{~mm}$ in length), another quarter of the specimens were reinforced with $5 \%$ of the same PPFs, another quarter of the specimens were reinforced with 1\% steel fibers (approximately $18 \mathrm{~mm}$ in length), and last quarter of the specimens were plain geopolymer. Next, the mixes were poured into the plastic molds, as shown in Figures 1 and 2. The specimens were hand-formed, and then the air bubbles were removed by vibrating. The molds were heated in the laboratory dryer for $24 \mathrm{~h}$ at $75{ }^{\circ} \mathrm{C}$. After the geopolymerization process, specimens were unmolded $[23,24]$. All of the geopolymer specimens were prepared at Cracow University of Technology (CUT).

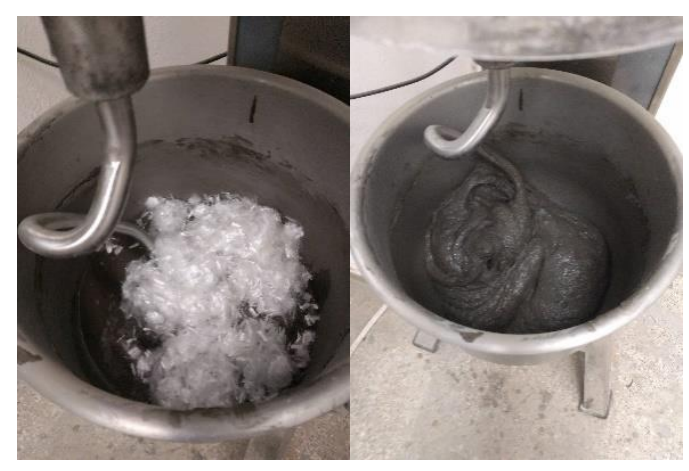

(a)

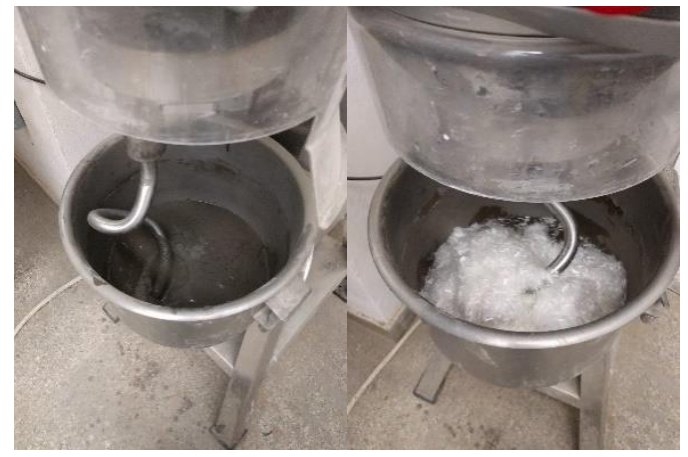

(b)

Figure 1. Geopolymer composite mixes, which were reinforced with $1 \%$ (a) and $5 \%$ (b) polypropylene fibers.

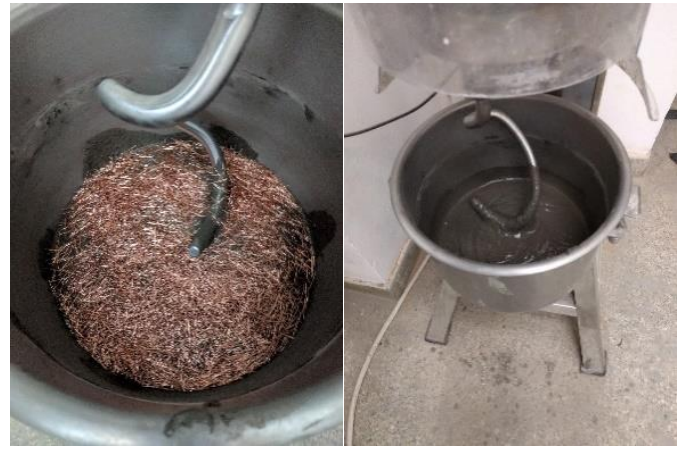

(a)

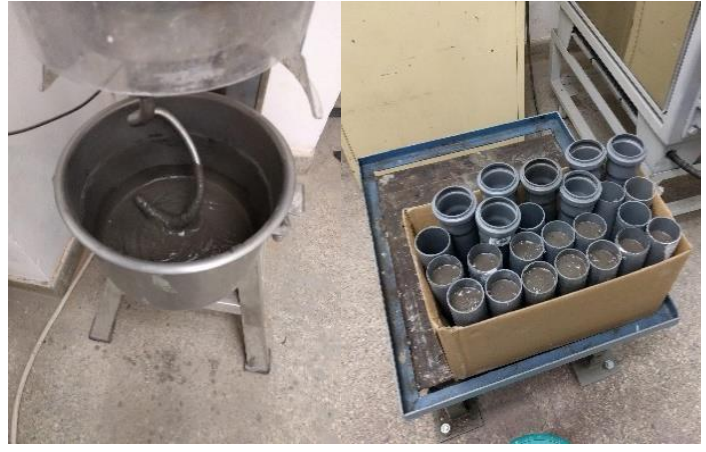

(b)

Figure 2. Geopolymer composite mixes, which were reinforced with $1 \%$ steel fibers reinforced (a) and plain (b).

For creep strain tests in compression, specimens were prepared according to RILEM TC 107-CSP recommendations [25]. All specimens were shaped to dimensions of $\varnothing 46 \times 190 \mathrm{~mm}$ or approximately 1:4 diameter to height ratio. For stain gauge attachment, 6 aluminum plates $(10 \times 15 \mathrm{~mm})$ were glued in pairs to each specimen. Afterwards, strain gauges were attached to those plates, as is shown in Figure 3a. Two aluminum plates were glued to the specimens to determine the shrinkage- one to the top and one to the bottom part of it. Hereupon, shrinkage specimens were placed in the measuring stand to determine the shrinkage strains throughout testing time, as is shown in Figure 3b. All the specimen preparatory work was done at Riga Technical University (RTU). Creep and shrinkage tests were carried out in a room with controlled atmosphere conditions: temperature $24 \pm 1{ }^{\circ} \mathrm{C}$ and relative humidity $30 \% \pm 3 \%$. 


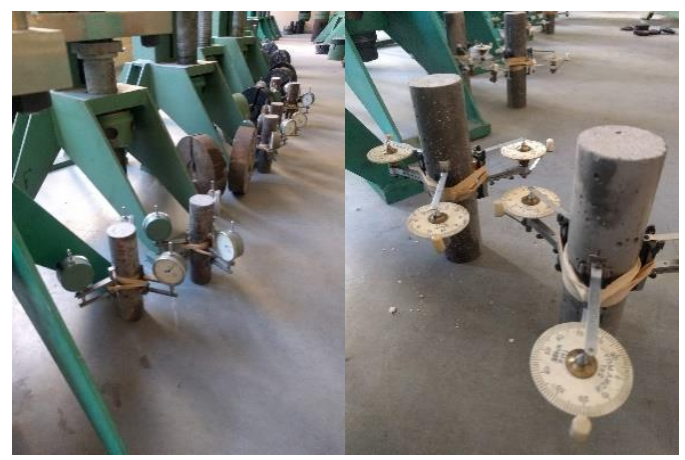

(a)

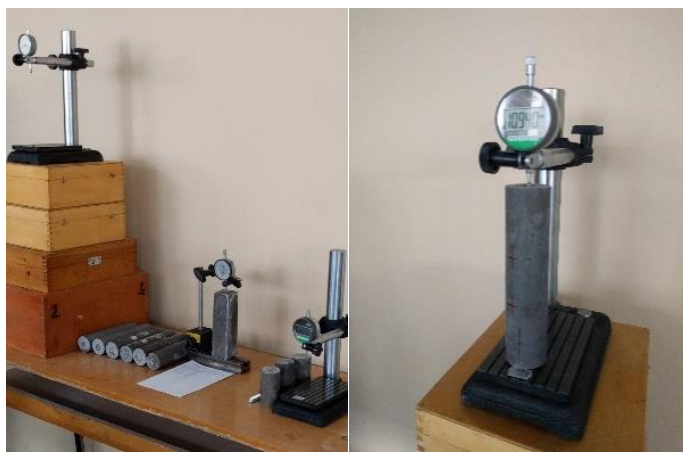

(b)

Figure 3. Prepared creep test specimens (a) and shrinkage specimens (b).

Shrinkage and creep strains were monitored every day for the first two weeks, after which they were monitored every other day. A constant load was applied throughout the whole creep testing period. The specimens were loaded with a load equivalent to $20 \%$ of the ultimate compressive strength, which was determined in compressive strength tests. Specimens were loaded gradually by $25 \%$ of the determined load in a short period (within 5 min). A creep test was carried out on tests stands, as is shown in Figure 4.

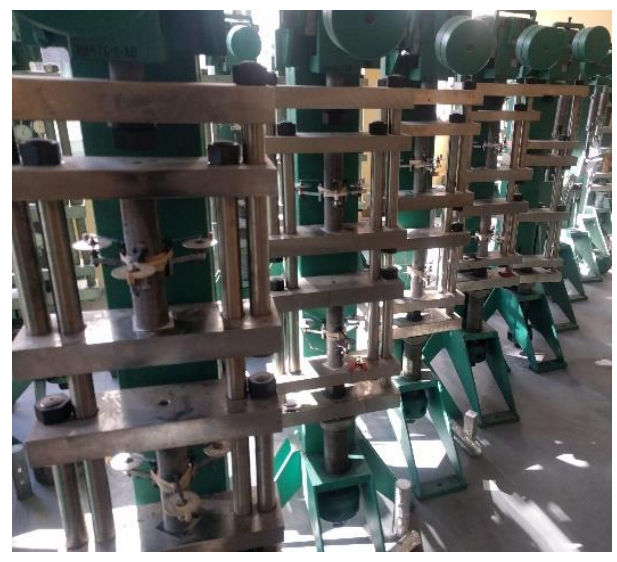

(a)

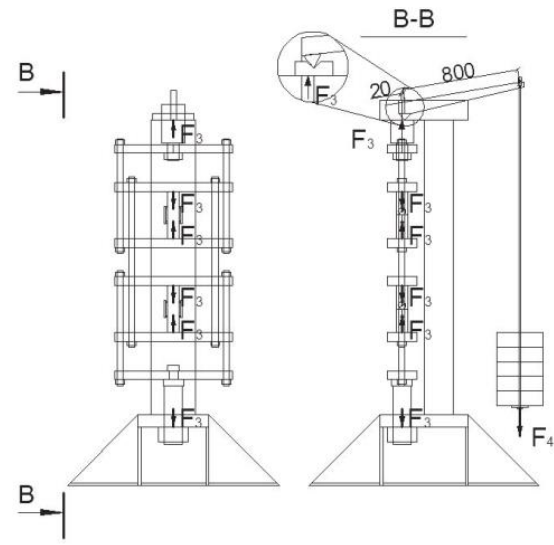

(b)

Figure 4. Creep test specimens set up in stands (a) and the test stand scheme (b) [26].

\section{Results and Discussion}

The compressive strength was determined before the creep tests. For each mix type, four specimens were used to determine compressive strength values. The specimen's age at the time of testing was 28 days. The compressive strength values are shown in Table 1 and Figure 5.

The applied load and counterweight amount necessary for creep test stands were calculated, considering the compressive strength values represented in Table 1. As Moradikhou states [27], the compressive strength improvement due to fiber incorporation is slight. However, with 5\% PPF and 1\% SF incorporation, the compressive strength is significantly lower. Ravinder et al. claimed that when fiber dosage increased from $0 \%$ to $0.3 \%$, the compressive strength increased by $6 \%$ [28]. From Figure 5, it is clear that 1\% PPF inclusion into the mix has improved the compressive strength of the composite. The compressive strength has increased by $4.9 \%$ in contrast to OGP. Other authors have observed that the compressive strength went up with a certain fiber inclusion amount, and when this amount is exceeded, the compressive strength drops significantly $[29,30]$. The compressive strength increased up until the fiber amount reached $0.60 \%$ by volume. Afterwards, the compressive 
strength of the tested high-strength concrete specimens drops significantly down to the compressive strength level of a plain high-strength concrete specimen (PPF reinforcement $0.9 \%$ by volume). Similarly, it is with geopolymer composites where specimens with $5 \%$ PPF incorporation show an $18.62 \mathrm{MPa}$ or a $35.5 \%$ drop from OGP compressive strength. Furthermore, the error amount in the compressive strength tests for the 5\% PPF reinforced composites are twice as big as those for plain geopolymer specimens; therefore, it seems that a higher amount of fiber incorporation into the composite does not only affect the mouldability of it but also an inner structure that significantly affects compressive strength.

Table 1. Compressive strength values of different types of specimens.

\begin{tabular}{cc}
\hline Test Specimen Type & Average Compressive Strength, MPa \\
\hline $\begin{array}{c}\text { Plain geopolymer composite } \\
\text { (OGP) }\end{array}$ & 52.5 \\
$\begin{array}{c}\text { Geopolymer composite with 1\% polypropylene } \\
\text { fibers (GP with 1\% PPF) }\end{array}$ & 55.1 \\
$\begin{array}{c}\text { Geopolymer composite with 5\% polypropylene } \\
\text { fibers (GP with 5\% PPF) }\end{array}$ & 33.9 \\
$\begin{array}{c}\text { Geopolymer composite with 1\% steel fibers } \\
\text { (GP with 1\% SF) }\end{array}$ & 48.4 \\
\hline
\end{tabular}

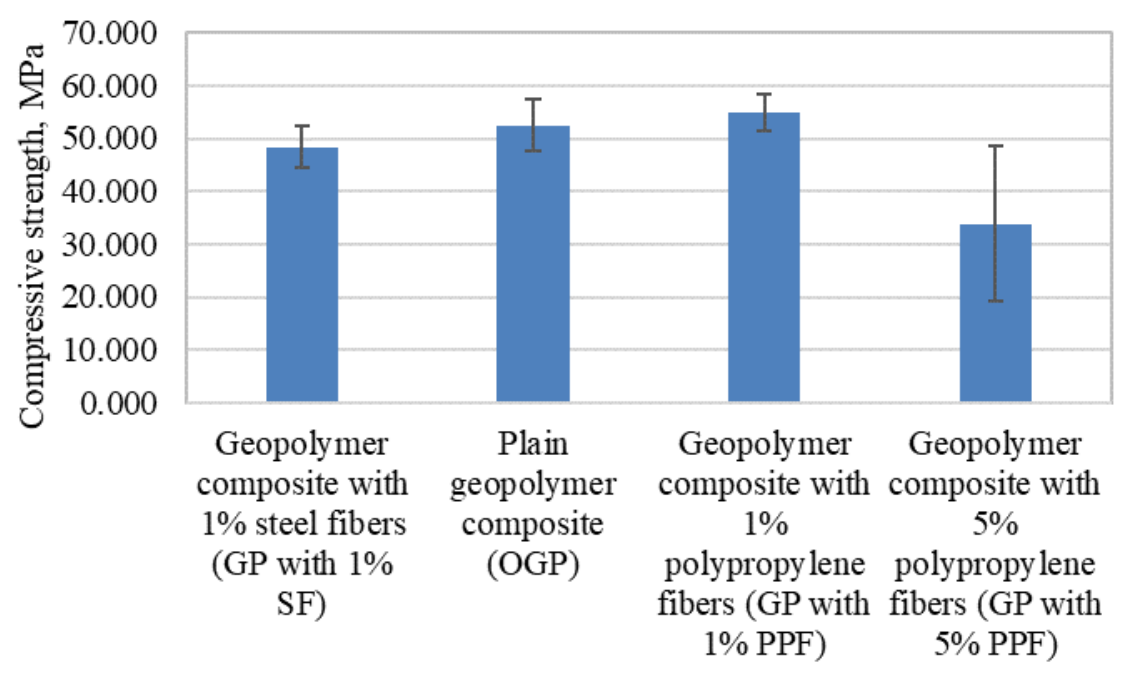

Figure 5. Geopolymer composite compressive strength values with measurement errors.

The creep and shrinkage tests were started after the first compressive strength test. Creep and shrinkage tests were carried out for 67 days.

The total strains and creep strains (total strains without shrinkage strains) are shown in Figure 6.

Figure $6 a, b$ show that the shrinkage strain amount is around $20 \%$ to $25 \%$ of all of the long-term total strain amount for all of the tested specimens. Notably, the shrinkage strains for the specimens with $1 \%$ steel fiber-reinforced geopolymer meaningly decrease, unlike the other geopolymer specimens. It is also visible that the creep strain curves have much slower strain, gaining capacity in the first 14 days without shrinkage strain. It is apparent that the geopolymer composite with $5 \%$ polypropylene fibers has the least amount of total strains and creep strains. Furthermore, the $1 \%$ steel fiber incorporation into the mix seems to not give any gains regarding creep strains and shrinkage strain reduction. Steel fiber incorporation has made it even worse than plain geopolymer. The creep strains for the $1 \%$ steel fiber geopolymer composite is, on average, $40 \%$ higher than the plain geopolymer. Additionally, a significant amount of elastic strains are observed in the curves of Figure 6. To evaluate creep strain amount, more thoroughly elastic strains were taken away (please see Figure 7). 


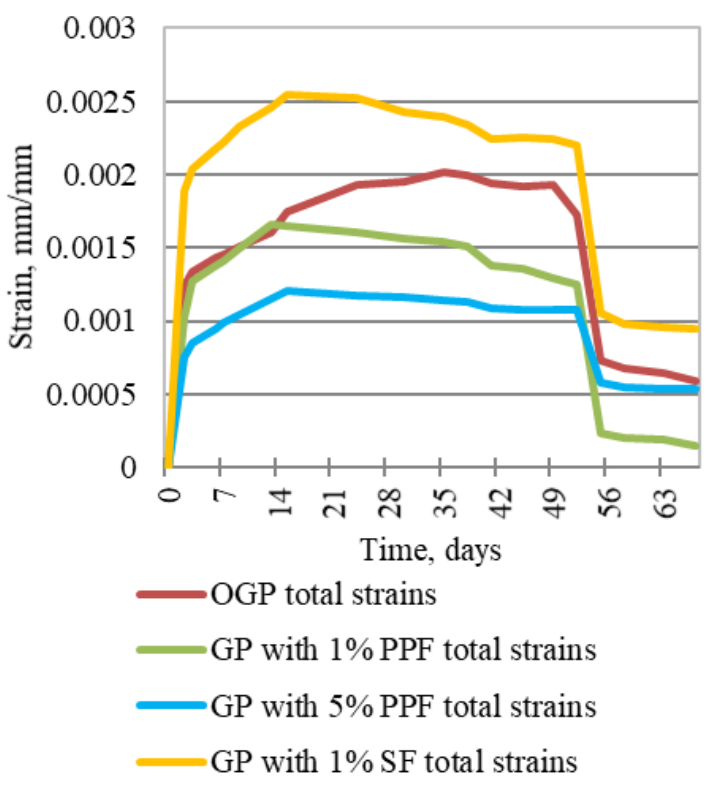

(a)

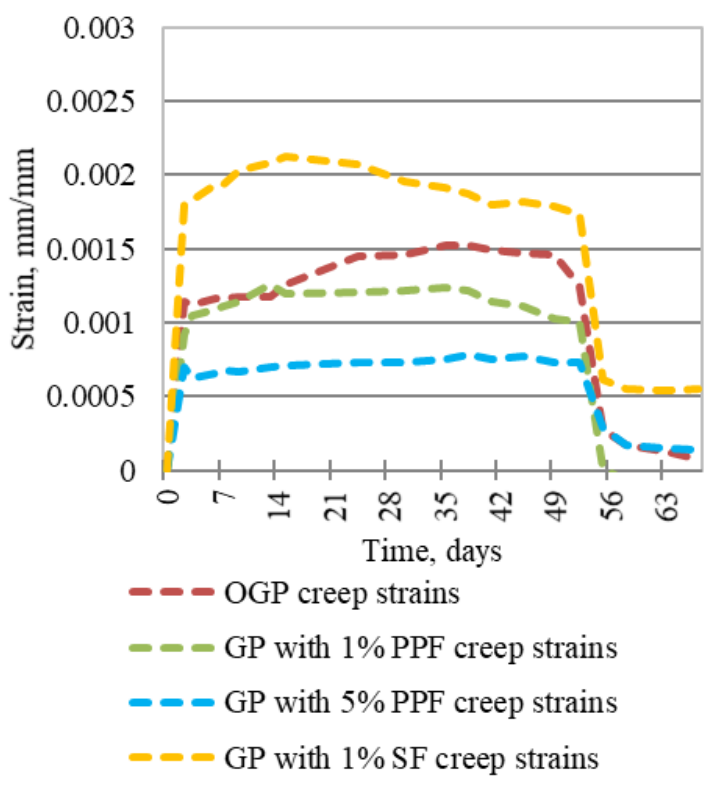

(b)

Figure 6. Reinforced and plain geopolymer composite total strains (a) and creep strains (b).

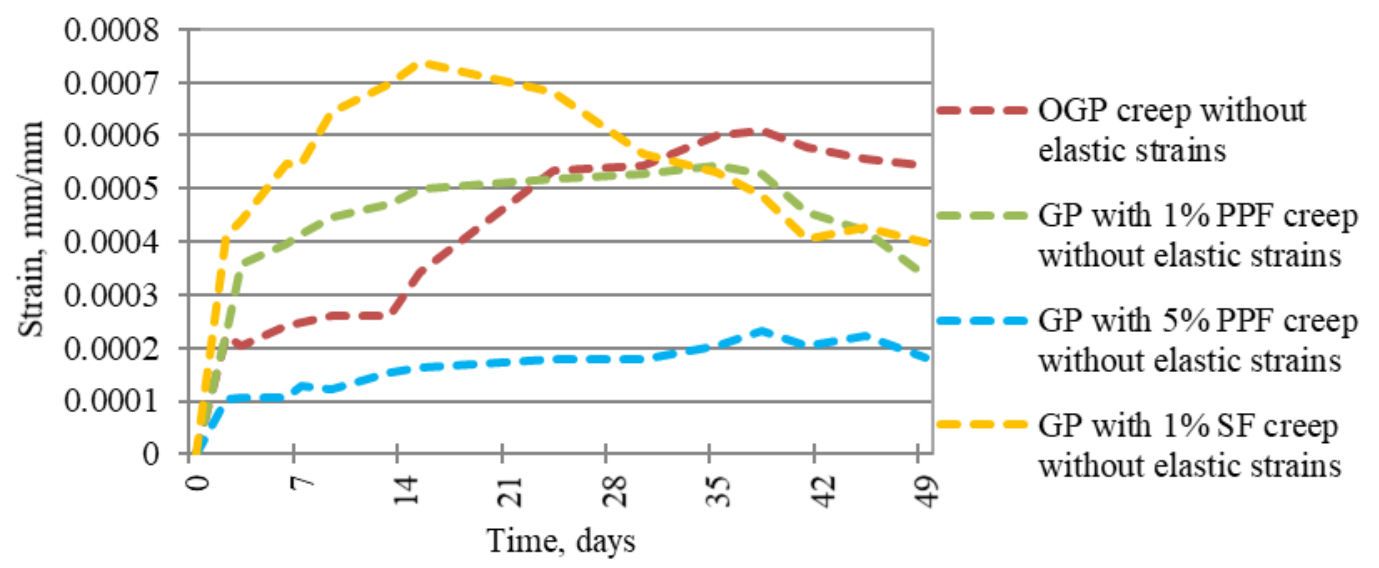

Figure 7. Creep strains without elastic strains of reinforced and plain geopolymer composite.

If the elastic strains are taken away, the relation of Figure $6 \mathrm{~b}$ for the first 28 days is still visible in Figure 7. It is apparent from reviewing Figures $6 \mathrm{~b}$ and 7 that the amount of elastic strains for the tested specimens varies from $68.5 \%$ to $80.9 \%$. The elastic strains for tested geopolymer composites are $80.9 \%, 77.6 \%, 75.0 \%$, and $68.5 \%$ for specimens with $5 \%$ PPF, $1 \%$ $\mathrm{SF}$, OGP, and $1 \%$ PPF, respectively. The highest creep strain was observed in the specimens that were reinforced with $1 \%$ steel fibers. The lowest creep strains were observed for the specimens that were reinforced with $5 \%$ polypropylene fiber.

Obtained results from long-term property tests and compressive strength tests lead to thinking that only a geopolymer composite with $1 \%$ PPF incorporation could be used for engineering purposes, such as repairing mortar or the prefabrication of plates. The $1 \%$ SF-reinforced geopolymer composite did not reach intended amount of load-bearing capacity, most likely due to an insufficient amount of fiber incorporation. The 5\% PPFreinforced geopolymer composite specimens showed the lowest creep strains. However, the compressive strength for these composites was the lowest and the greatest margin of error within the tested specimens. Additionally, these specimens had the highest elastic strain of all the tested specimens. Therefore, it is apparent that reinforcement amount for the $5 \%$ PPF 
reinforced geopolymer composite specimens was too much, and the reinforcement amount of 3\% could represent a sufficient amount of PPF reinforcement. As for the shrinkage, the 1\% PPF and 5\% PPF showed the lowest values, followed by the $1 \%$ SF and OGP. The $5 \%$ PPF-reinforced composite showed, on average, a $27.27 \%, 60.33 \%$, and $63.20 \%$ lower shrinkage strains than the 1\% PPF-reinforced geopolymer composite, the $1 \%$ SF-reinforced composite, and the OGP composite, respectively.

\section{Conclusions}

Long-term properties of fly ash-based geopolymer composite with various amounts and kinds of reinforcement were determined by performing 67-day creep and shrinkage tests. Additionally, compressive strength was determined before the long-term testing. Results of the research showed the following findings:

- The geopolymer composite with 5\% polypropylene fiber incorporation had the highest creep resistance of all types of specimens, followed by specimens with $1 \%$ polypropylene fiber reinforcement, the plain geopolymer, and specimens with $1 \%$ steel fiber reinforcement. At the peak, the geopolymer with 1\% polypropylene fiber had 1.40 times higher creep strains. In comparison, the geopolymer without reinforcement and with $1 \%$ steel fiber had values that were 1.99 and 2.44 times higher, respectively.

- If the elastic strains are exempt, then the $5 \%$ polypropylene fiber reinforced geopolymer showed the smallest amount of creep strains, followed by the $1 \%$ polypropylene fiberreinforced specimen, the $1 \%$ steel fiber-reinforced specimen, and the plain geopolymer specimen. The creep deformation differences were 1.84, 2.19, and 2.99 times, respectively.

- The specimens with 5\% polypropylene had the least elastic strains, followed by the $1 \%$ polypropylene-reinforced specimen, the plain specimen, and the $1 \%$ steel fiber-reinforced geopolymer composite specimen. The difference were 1.25, 1.67, and 2.52 times, respectively.

- Each type of reinforcement was observed to have its own optimal amount that contributes to increased material mechanical and long-term properties. A 10-M geopolymer composite incorporating 1\% polypropylene fibers was observed to improve the compressive strength, providing low creep and shrinkage strains. Specimens with 5\% polypropylene fiber reinforcement were observed to have the lowest creep and second lowest shrinkage strains. They also were observed to have the lowest compressive strength of all of the tested specimens.

Author Contributions: Data curation, R.G. and T.K.; Formal analysis, R.G.; Resources, L.R.; Supervision, A.S. and L.P.; Writing—original draft, R.G.; Writing—review \& editing, A.S., T.K. and N.V. All authors have read and agreed to the published version of the manuscript.

Funding: This research was partially funded by the Ministry of Science and Higher Education of the Russian Federation as part of World-class Research Center program: Advanced Digital Technologies (contract No. 075-15-2020-934 dated 17 November 2020). This work was supported by the European Regional Development Fund within the Activity 1.1.1.2 "Post-doctoral Research Aid" of the Specific Aid Objective 1.1.1 "To increase the research and innovative capacity of scientific institutions of Latvia and the ability to attract external financing, investing in human resources and infrastructure" of the Operational Programme "Growth and Employment" (No.1.1.1.2/VIAA/3/19/401). This publication was supported by Riga Technical University's Doctoral Grant programme.

Conflicts of Interest: The authors declare no conflict of interest.

\section{References}

1. Yan, S.; He, P.; Jia, D.; Wang, J.; Duan, X.; Yang, Z.; Wang, S.; Zhou, Y. Effects of high-temperature heat treatment on the microstructure and mechanical performance of hybrid Cf-SiCf-(Al2O3p) reinforced geopolymer composites. Compos. Part B Eng. 2017, 114, 289-298. [CrossRef]

2. Lokuge, W.; Wilson, A.; Gunasekara, C.; Law, D.W.; Setunge, S. Design of fly ash geopolymer concrete mix proportions using Multivariate Adaptive Regression Spline model. Constr. Build. Mater. 2018, 166, 472-481. [CrossRef] 
3. Galiano, Y.L.; Leiva, C.; Villegas, R.; Arroyo, F.; Vilches, L.; Fernández, C.L. Carbon fiber waste incorporation in blast furnace slag geopolymer-composites. Mater. Lett. 2018, 233, 1-3. [CrossRef]

4. Pan, Z.; Sanjayan, J.G.; Collins, F. Effect of transient creep on compressive strength of geopolymer concrete for elevated temperature exposure. Cem. Concr. Res. 2014, 56, 182-189. [CrossRef]

5. Nguyen, K.; Le, T.A.; Lee, K. Evaluation of the mechanical properties of sea sand-based geopolymer concrete and the corrosion of embedded steel bar. Constr. Build. Mater. 2018, 169, 462-472. [CrossRef]

6. Sele, L.; Bajare, D.; Bumanis, G.; Dembovska, L. Alkali Activated Binders Based on Metakaolin. Environ. Technol. Resour. Proc. Int. Sci. Pract. Conf. 2015, 1, 200-204. [CrossRef]

7. Wallah, S.E.; Rangan, B.V. Low-Cakcium Fly Ash Based. 2006, pp. 1-107. Available online: https://espace.curtin.edu.au/handle/ 20.500.11937/34322 (accessed on 6 May 2021).

8. Sagoe-Crentsil, K.; Brown, T.; Taylor, A. Drying shrinkage and creep performance of geopolymer concrete. J. Sustain. Cem. Mater. 2013, 2, 35-42. [CrossRef]

9. Chen, S.; Wu, C.; Yan, D. Binder-scale creep behavior of metakaolin-based geopolymer. Cem. Concr. Res. 2019, 124, 105810. [CrossRef]

10. Khan, I.; Xu, T.; Castel, A.; Gilbert, R.I.; Babaee, M. Risk of early age cracking in geopolymer concrete due to restrained shrinkage. Constr. Build. Mater. 2019, 229, 116840. [CrossRef]

11. Nizina, T.; Balykov, A. Experimental-statistical models of properties of modified fiber-reinforced fine-grained concretes. Mag. Civ. Eng. 2016, 62, 13-25. [CrossRef]

12. Lee, N.; Jang, J.; Lee, H. Shrinkage characteristics of alkali-activated fly ash/slag paste and mortar at early ages. Cem. Concr. Compos. 2014, 53, 239-248. [CrossRef]

13. Kuenzel, C.; Li, L.; Vandeperre, L.; Boccaccini, A.; Cheeseman, C. Influence of sand on the mechanical properties of metakaolin geopolymers. Constr. Build. Mater. 2014, 66, 442-446. [CrossRef]

14. Ranjbar, N.; Talebian, S.; Mehrali, M.; Kuenzel, C.; Metselaar, H.S.C.; Jumaat, M.Z. Mechanisms of interfacial bond in steel and polypropylene fiber reinforced geopolymer composites. Compos. Sci. Technol. 2016, 122, 73-81. [CrossRef]

15. Ranjbar, N.; Mehrali, M.; Mehrali, M.; Alengaram, U.J.; Jumaat, M.Z. High tensile strength fly ash based geopolymer composite using copper coated micro steel fiber. Constr. Build. Mater. 2016, 112, 629-638. [CrossRef]

16. Ranjbar, N.; Zhang, M. Fiber-reinforced geopolymer composites: A review. Cem. Concr. Compos. 2020, 107, 103498. [CrossRef]

17. Das, C.S.; Dey, T.; Dandapat, R.; Mukharjee, B.B.; Kumar, J. Performance evaluation of polypropylene fibre reinforced recycled aggregate concrete. Constr. Build. Mater. 2018, 189, 649-659. [CrossRef]

18. Xin, C.; Wang, Z.; Zhou, J.; Gao, B. Shaking table tests on seismic behavior of polypropylene fiber reinforced concrete tunnel lining. Tunn. Undergr. Space Technol. 2019, 88, 1-15. [CrossRef]

19. Qin, Y.; Zhang, X.; Chai, J.; Xu, Z.; Li, S. Experimental study of compressive behavior of polypropylene-fiber-reinforced and polypropylene-fiber-fabric-reinforced concrete. Constr. Build. Mater. 2019, 194, 216-225. [CrossRef]

20. Marcos-Meson, V.; Fischer, G.; Edvardsen, C.; Skovhus, T.; Michel, A. Durability of Steel Fibre Reinforced Concrete (SFRC) exposed to acid attack-A literature review. Constr. Build. Mater. 2019, 200, 490-501. [CrossRef]

21. Ruiz, G.; de la Rosa, Á.; Poveda, E. Relationship between residual flexural strength and compression strength in steel-fiber reinforced concrete within the new Eurocode 2 regulatory framework. Theor. Appl. Fract. Mech. 2019, 103, 102310. [CrossRef]

22. Han, J.; Zhao, M.; Chen, J.; Lan, X. Effects of steel fiber length and coarse aggregate maximum size on mechanical properties of steel fiber reinforced concrete. Constr. Build. Mater. 2019, 209, 577-591. [CrossRef]

23. Korniejenko, K. Geopolymers for Increasing Durability for Marine Infrastructure. Spec. Publ. 2018, 326, 20.1-20.10.

24. Łach, M.; Mikuła, J.; Hebda, M. Thermal analysis of the by-products of waste combustion. J. Therm. Anal. Calorim. 2016, 125, 1035-1045. [CrossRef]

25. Acker, P.; Agullo, L.; Auperin, M.; Carol, I.; Carreira, D.J.; Catarino, J.M. Rilem tc 107-csp: Creep and shrinkage prediction models: Principles of their formation recommendation measurement of time-dependent strains of concrete. Mater. Struct. 1998, 31, 507-512.

26. Sprince, A.; Pakrastinsh, L.; Baskers, B.; Gaile, L. Crack Development Research in Extra Fine Aggregate Cement Composites. Environ. Technol. Resour. Proc. Int. Sci. Pract. Conf. 2015, 1, 205-208. [CrossRef]

27. Moradikhou, A.B.; Esparham, A.; Avanaki, M.J. Physical \& mechanical properties of fiber reinforced metakaolin-based geopolymer concrete. Constr. Build. Mater. 2020, 251, 118965. [CrossRef]

28. Ravinder, R.; Kumar, V.; Kumar, C.; Prakash, A.; Krishna, P.V. Strength Characteristics of Fibrous Self Curing Concrete Using Super Absorbent Polymer. In Proceedings of the National Conference on Recent Advances in Civil Engineering, Coimbatore, India, 8-9 May 2019.

29. Ahmed, T.W.; Ali, A.A.M.; Zidan, R.S. Properties of high strength polypropylene fiber concrete containing recycled aggregate. Constr. Build. Mater. 2020, 241, 118010. [CrossRef]

30. Yap, S.P.; Bu, C.H.; Alengaram, U.J.; Mo, K.H.; Jumaat, M.Z. Flexural toughness characteristics of steel-polypropylene hybrid fibre-reinforced oil palm shell concrete. Mater. Des. 2014, 57, 652-659. [CrossRef] 